\title{
Evaluation of members of the TGF $\beta$ superfamily as candidates for the oocyte factors that control mouse cumulus expansion and steroidogenesis
}

\author{
B. C. Vanderhyden ${ }^{1}$, E. A. Macdonald ${ }^{1}$, E. Nagyova ${ }^{2}$
} and A. Dhawan ${ }^{1}$

'Department of Cellular and Molecular Medicine, University of Ottawa, Ottawa Regional Cancer Centre, 503 Smyth Road, Ottawa, Canada K1H 1C4; and ${ }^{2}$ Institute of Animal Physiology and Genetics, Libechov, Czech Republic

Oocytes secrete factors that control cumulus and granulosa functions, including cumulus expansion and steroid hormone production. Some members of the transforming growth factor $\beta$ (TGF $\beta$ ) superfamily influence these activities, yet it is still not determined conclusively whether any of these superfamily members are the previously reported oocytesecreted factors. The aim of this study was to examine the effects of TGF $\beta 1$ and growth differentiation factor 9 (GDF-9) on cumulus expansion and progesterone production by mouse oocytectomized (OOX) complexes in culture. TGF $\beta 1$ mimics the effects of oocytes by both enabling cumulus expansion and inhibiting progesterone production; however, neutralizing antibodies to TGF $\beta 1$ in cultures of cumulus-oocyte complexes (COCs) or in co-cultures of OOX complexes failed to inhibit the ability of oocytes to enable cumulus expansion or inhibit progesterone production. Activin A had no effect on progesterone production by OOX complexes. In experiments using oocytes obtained from mice with deficient expression of GDF-9, OOX complexes cultured in the presence of heterozygous oocytes were capable of full expansion, whereas OOX complexes cultured with oocytes from GDF-9 null mice did not expand. Similarly, GDF-9 null oocytes failed to suppress $\mathrm{FSH}$-induced progesterone production by OOX complexes. These results support the hypothesis that GDF-9 is the cumulus expansion enabling factor produced by mouse oocytes and that GDF-9 also inhibits cumulus progesterone production; however, the possibility remains that loss of GDF-9 may indirectly affect the ability of oocytes to produce the factors that regulate cumulus cell activity.

\section{Introduction}

The process of follicular development is an elaborately orchestrated event that involves bidirectional communication between germ cells and somatic cells. Communication between 
the oocyte and surrounding granulosa cells occurs via both membrane gap junctions (Heller and Schultz, 1980) and paracrine factors (Eppig et al, 1997a). For example, the expression of Kit ligand (KL) by granulosa cells (Manova et al., 1993; Ismail et al., 1996) and KL activation of the Kit tyrosine kinase receptors in oocytes plays a key role in oocyte growth and follicle development (Packer et al., 1994; Yoshida et al., 1997).

Of particular interest in the past decade has been the secretion of paracrine factors by the oocyte that mediate several key functions in the regulation of granulosa cell proliferation and differentiated activity. The suggestion that granulosa cells are dependent upon the oocyte for development and function was evident when ovectomy of rabbit follicles resulted in the luteinization of granulosa cells (El-Fouly et al., 1970). Additional evidence for such a factor was provided by in vivo and in vitro experiments in rats and rabbits, showing that the removal, absence or destruction of oocytes leads to granulosa cell luteinization (Nekola and Nalbandov, 1971; Hubbard and Erickson, 1988). The procedure of oocytectomy has been used to show that oocyte-secreted factors regulate steroidogenesis in mouse, rat, pig and bovine granulosa cells (Vanderhyden et al., 1993; Coskun et al., 1995; Vanderhyden and Tonary, 1995; Li et al, 2000). Factors produced by oocytes inhibit expression of LH receptors in granulosa cells, which contributes to their actions as luteinization inhibitors (Eppig et al , 1997b). In addition to inhibiting luteinization, oocytes further promote follicle development by secreting a soluble factor that enhances the proliferation of mouse (Vanderhyden et al., 1992; Gilchrist et al., 2001) and bovine (Lanuza et al., 1998; Li et al, 2000) granulosa cells. Finally, soluble factors produced by mouse, rat, pig and bovine oocytes enable the expansion of mouse oocytectomized (OOX) cumulus complexes (Buccione et al., 1990; Vanderhyden, 1993; Ralph et al,, 1995) by promoting the ability of cumulus cells to produce hyaluronic acid (Buccione et al., 1990) and by suppressing expression of urokinase plasminogen activator (Canipari et al., 1995).

The identification of the oocyte-secreted factors has been difficult and none are yet confirmed, but members of the transforming growth factor $\beta$ (TGF $\beta$ ) superfamily have aroused considerable interest by their ability to mimic the actions of the oocyte in regulating granulosa cell activities, specifically steroidogenesis and enabling of cumulus expansion. Some members of this family, growth differentiation factor 9 (GDF-9), bone morphogenetic protein 15 (BMP-15) and BMP-6, are expressed by oocytes and, therefore, are logical candidates to consider as possible mediators of the effects attributed to the oocyte. The expression of both GDF-9 and BMP-15 in mice begins in oocytes of small primary follicles and continues throughout ovulation (McGrath et al., 1995; Dube et al., 1998), whereas GDF-9 expression in bovine and ovine ovaries is detectable from the primordial stage of follicle development (Bodensteiner et al., 1999), indicating a potential role for GDF-9 in the initiation of folliculogenesis in domestic ruminants. The actions of GDF-9 on steroidogenesis in granulosa cells may be species-dependent and are strongly affected by the presence of gonadotrophins, as recombinant GDF-9 stimulates steroidogenic acute regulatory protein (StAR) expression and progesterone secretion by murine granulosa cells (Elvin et al., 1999a), whereas GDF-9 suppresses FSH-stimulated progesterone and oestradiol production by rat granulosa cells (Vitt et al., 2000). BMP-6 (Otsuka et al., 2001a) and BMP-15 (Otsuka et al., 2000) also suppress FSH-stimulated progesterone production by rat granulosa cells rendering these growth factors possible candidates for the progesterone regulatory factor secreted by oocytes.

Activin, although initially characterized as a gonadal hormone that regulates the pituitary release of FSH (Ling et al., 1986; Vale et al., 1986), may play a role in the regulation of oocyte activity. Activin is produced by granulosa cells (Findlay, 1993), and both oocytes and granulosa cells have activin receptors (Wu et al., 1994; Drummond et al., 2002). However, activin subunits $\beta_{A}$ and $\beta_{B}$ transcripts have been detected in Xenopus oocytes (Rebagliati and 
Dawid, 1993) and immunocytochemical studies have shown that activin protein is present in mouse oocytes (Albano et al., 1993), Previous studies have demonstrated the developmentdependent effects of activin on granulosa cell steroidogenesis, such that aromatase activity is enhanced, P450scc activity is inhibited, and progesterone production is suppressed as follicular maturation progresses (Miró el al., 1991). As activin is expressed by oocytes and can suppress progesterone production, it too should be investigated as a candidate for one of the oocyte-secreted factors.

In terms of cumulus expansion, TGF 31 mimics the oocyte-secreted factor in stimulating hyaluronic acid synthesis by rat and mouse cumulus cells in the presence of FSH (Salustri et al., 1990; Tirone et al., 1997). However, TGFB1 is less effective than the oocyte factor, and TGF $\beta 1$ neutralizing antibodies do not inhibit the response to the oocyte factor (Salustri et al., 1990), indicating that TGF $\beta 1$ is not the cumulus expansion enabling factor (CEEF). However, because the cumulus cells were plated as monolayers in previous studies, the loss of the three-dimensional organization of the cumulus cells may alter the responsiveness of the cumulus cells to TGF $\beta 1$ and, therefore, it is important to determine whether TGF $\beta 1$ has activity resembling CEEF using cumulus cells that have maintained their spatial integrity.

GDF-9 has also been shown to enable cumulus expansion in the absence of the oocyte; however, at this time the only evidence to support the hypothesis that GDF-9 is the oocytesecreted CEEF is the observation that recombinant GDF-9 stimulates cumulus expansion in OOX complexes (Elvin et al, 1999a). Although GDF-9 is expressed in oocytes throughout follicle development, it has not yet been demonstrated that GDF-9 is secreted by oocytes at the appropriate stage of development, or that GDF-9 null oocytes have lost the ability to secrete the expansion enabling activity.

The actions of many of the TGF $\beta$ family members on granulosa cell activity seem to be dependent on the context, particularly as it relates to stage of follicle development, the presence of gonadotrophins and the species. Therefore, in the present study, activin-A, TGF $\beta 1$ and GDF-9 were assessed for their ability to enable cumulus expansion and regulate steroidogenesis of murine cumulus cells, using the system of oocytectomized complexes that was used in the original studies to determine the presence and activity of the oocyte-secreted factors. Specifically, the objectives of this study were to investigate the effects of TGF $\beta 1$ and activin $\mathrm{A}$ on cumulus expansion and steroid hormone production by OOX complexes, and to determine the ability of GDF-9 deficient oocytes to regulate cumulus expansion and steroid hormone production by OOX complexes.

\section{Materials and Methods}

\section{Isolation and co-culture of denuded oocytes with OOX complexes}

Cumulus-oocyte complexes (COCs) were obtained from antral follicles of 24- to 28-dayold $(\mathrm{C} 57 \mathrm{BL} / 6 \times \mathrm{Balb} / \mathrm{c}) \mathrm{F}_{1}$ mice at $40-44 \mathrm{~h}$ after i.p. injection with 5 iu equine chorionic gonadotrophin (eCG). Denuded oocytes and OOX complexes were prepared as described by Vanderhyden et al. (1990) and then cultured in Waymouth media with 5\% fetal bovine serum (WAY/FBS), In some experiments, denuded oocytes were obtained from GDF-9-deficient mice (generously provided by M. Matzuk, Baylor College of Medicine; Dong et al., 1996). Southern blot analysis was used to determine the genotype of mice. Wild-type, heterozygous and homozygous oocytes were collected by injecting mice with 5 iu eCG and, 2 days later, preparing denuded oocytes from GDF- $9+/+$ and $+/$ - mice as described above. GDF-9-deficient -1 - ovaries were placed in WAY/FBS containing collagenase $\left(3 \mathrm{mg} \mathrm{ml}^{-1}\right)$ for approximately $45 \mathrm{~min}$, and intermittent pipetting with a Pasteur pipette was performed to denude the oocytes 


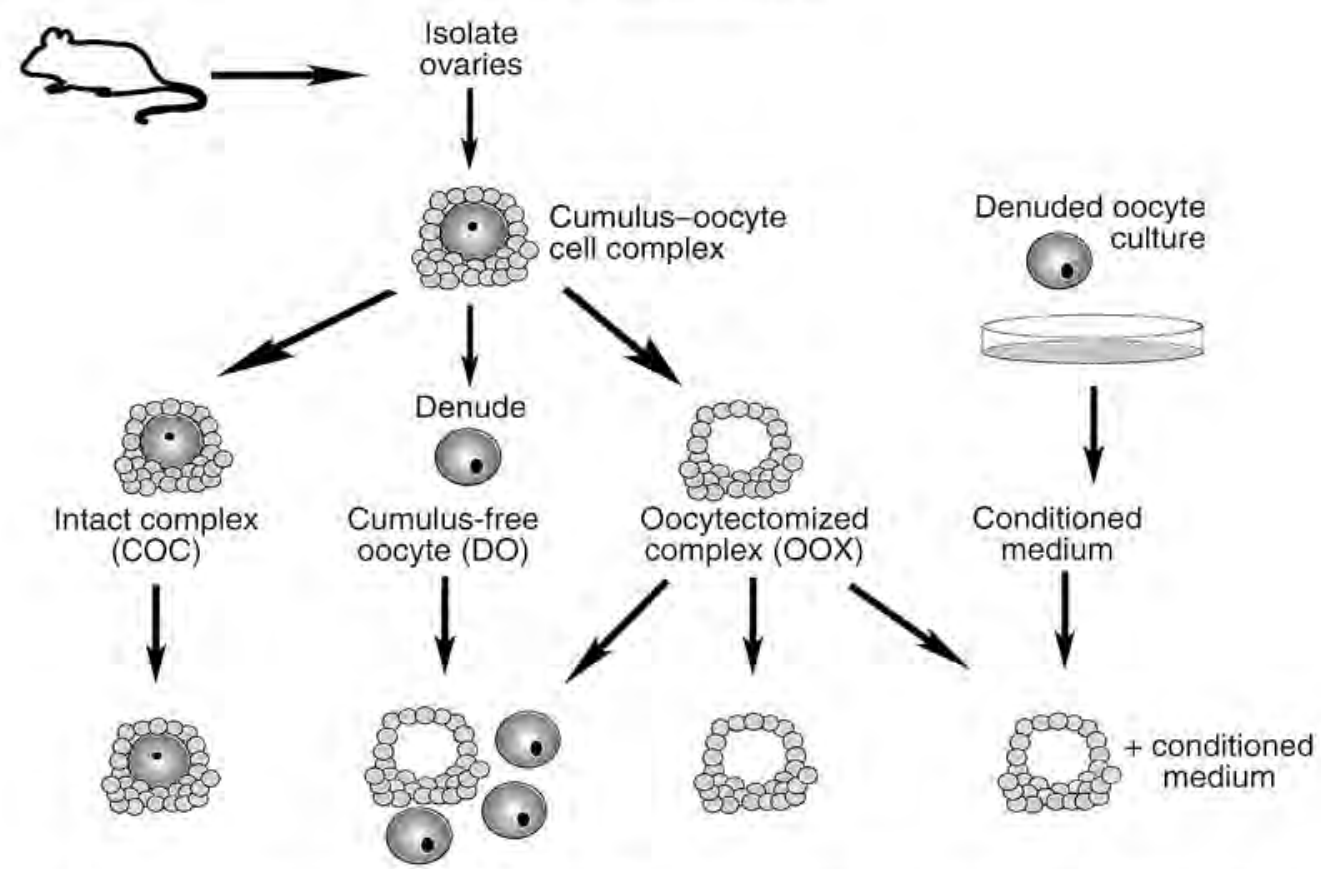

Fig. 1. Standard procedure for determining the effects of oocytes on cumulus cell function. Oocytectomy removes the oocytes from the complexes, retaining the three-dimensional integrity and the cell-cell associations in the complex. Comparisons are made between the intact cumulusoocyte complexes (COCs), the oocytectomized cumulus-oocyte cell (OOX) complexes and OOX complexes either co-cultured with denuded oocytes (DO) or cultured in media conditioned for $24 \mathrm{~h}$ with denuded oocytes.

of granulosa cells. Denuded oocytes were washed three times in WAY/FBS, cultured for 4-5 h to allow spontaneous meiotic maturation and then co-cultured with OOX complexes. The general experimental procedure is outlined (Fig. 1).

\section{Cumulus expansion}

The effects of TGF $\beta 1$ on expansion of mouse OOX complexes was tested by culturing ten OOX in $50 \mu \mathrm{l}$ drops of WAY/FBS under washed oil in $35 \mathrm{~mm}$ Petri dishes. Complexes were treated with FSH $\left(100 \mathrm{ng} \mathrm{ml}^{-1}\right.$ ) or $10 \mathrm{ng} \mathrm{TGFB1} \mathrm{ml}^{-1}$ (R\&D Systems, Minneapolis, MN), or both in combination. Neutralizing antibodies to TGF $\beta 1\left(5 \mu \mathrm{g} \mathrm{ml}^{-1} ;\right.$ R\&D Systems) were added to some drops to determine the specificity of action of TGF $\beta 1$ and to confirm the efficacy of the antibodies. The ability of GDF-9-deficient oocytes to enable cumulus expansion was assessed by culturing OOX complexes alone or in the presence of either 25 heterozygous $(+/-)$ or homozygous (-l-) meiotically competent (MC) or incompetent (MI) denuded oocytes (that is, one oocyte per $2 \mu \mathrm{l}$ ). The complexes were cultured for $16 \mathrm{~h}$ at $37^{\circ} \mathrm{C}$ in $5 \% \mathrm{CO}_{2}: 5 \%$ $\mathrm{O}_{2}: 90 \% \mathrm{~N}_{2}$ and then assessed for cumulus expansion using a subjective scoring system that ranges from 0 (no response) to +4 (maximal expansion; Buccione et al., 1990).

\section{Steroidogenesis}

The effects of TGF $\beta 1$ and activin A on steroid hormone production by mouse cumulus cells were determined by culturing ten COCs or OOX complexes in $250 \mu \mathrm{l}$ WAY/FBS. In some wells, 
Table 1. Transforming growth factor $\beta 1$ (TGF $\beta 1$ ) mimics the effects of the cumulus expansion-enabling factor secreted by mouse oocytes

\begin{tabular}{lcc}
\hline & \multicolumn{2}{c}{ Degree of expansion $^{\mathrm{a}}$} \\
\cline { 2 - 3 } Treatment & $\mathrm{COC}(n)$ & OOX $(n)$ \\
\hline FSH & +3 to $+4(60)$ & $0(70)$ \\
TGF 1 & - & $0(30)$ \\
FSH + TGF 31 & +3 to $+4(20)$ & +2 to $+3(110)$ \\
FSH + TGF $1-\mathrm{Ab}$ & $+3(40)$ & $0(20)$ \\
FSH + TGF $1+$ TGFB1-Ab & $+3(40)$ & $0(70)$ \\
OCM + FSH & +3 to $+4(60)$ & +3 to $+4(60)$ \\
OCM + FSH + TGF $31-A b$ & $+3(50)$ & $+3(70)$ \\
\hline
\end{tabular}

aDegree of expansion was determined on a scale from 0 (no expansion) to +4 (maximum response with all cumulus layers undergoing expansion).

COC: cumulus-oocyte complexes; OOX: oocytectomized oocyte-cumulus cell complexes: TGFB1-Ab: neutralizing antibodies to TGF 1 ; OCM: oocyte-conditioned media: media collected from plates of denuded oocytes cultured for $24 \mathrm{~h} ;-;$ not performed.

the OOX complexes were co-cultured with 125 denuded, 5 fully-grown oocytes. Complexes were cultured for $30-48 \mathrm{~h}$ in the presence or absence of $10 \mathrm{ng}$ TGF $31 \mathrm{ml}^{-1}$ or $7.5-120.0 \mathrm{ng}$ activin $A \mathrm{ml}^{-1}$. Neutralizing antibodies to TGF $\beta 1\left(5 \mu \mathrm{g} \mathrm{ml}^{-1}\right.$; R\&D Systems) were added to some wells to determine the specificity of action of TGF 31 . The ability of GDF-9-deficient oocytes to regulate progesterone and oestradiol production by the granulosa cells was assessed by culturing OOX complexes alone or with either 75 heterozygous $(+/-)$ or 75 homozygous $(-/)$ meiotically competent or incompetent denuded oocytes. Denuded oocytes were cultured for $24 \mathrm{~h}$ in $100 \mu \mathrm{l}$ WAY/FBS before the addition of the OOX complexes. In all experiments, FSH (100 $\left.\mathrm{ng} \mathrm{ml}^{-1}\right)$ and testosterone $\left(500 \mathrm{nmoll}^{-1}\right.$; Sigma, St Louis, MO) were added to the culture media to support oestradiol production. After $48 \mathrm{~h}$, culture media were collected and stored at $-20^{\circ} \mathrm{C}$ until assayed for progesterone and oestradiol by radioimmunoassays as described by Vanderhyden and Tonary (1995).

\section{Statistical analysis}

All experiments were performed at least three times, with different pools of ovaries. When comparing multiple groups, data were expressed as mean \pm standard error of the mean, and statistical comparison was made using ANOVA with Newman-Keul's test for multiple comparisons. Statistical comparisons of two groups were made using unpaired, two-tailed $t$ tests for normal distributions. Statistical significance was inferred at $P<0.05$.

\section{Results}

\section{TGF $\beta 1$ mimics CEEF in OOX complexes}

Given that a previous study demonstrated an effect of TGF $\beta 1$ on dispersed cumulus cells (Salustri et $\left.a l_{*}, 1990\right)$, the first experiment addressed whether cellular associations may alter this response by examining the effect of TGFB1 on expansion of mouse OOX complexes. FSH stimulated expansion of intact COCs to almost maximal levels $(+3$ to +4$)$, but oocytectomy rendered the complexes unable to expand in response to FSH (Table 1). TGF 31 alone had no effect on OOX complexes, but was quite effective at promoting the expansion of FSH-treated OOX complexes, although the overall degree of expansion was not as great as 
(a)

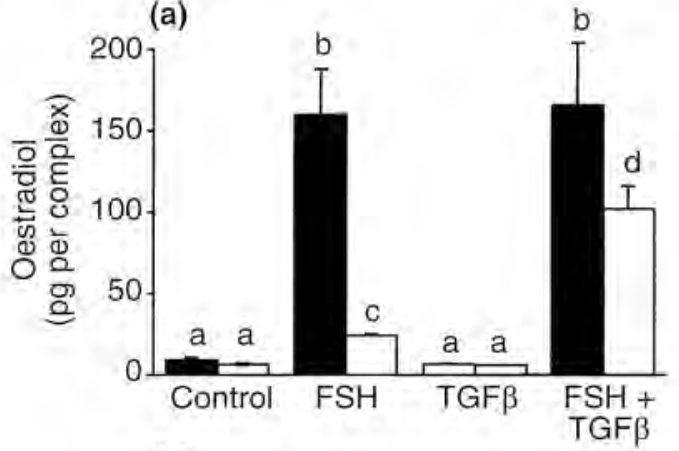

(b)

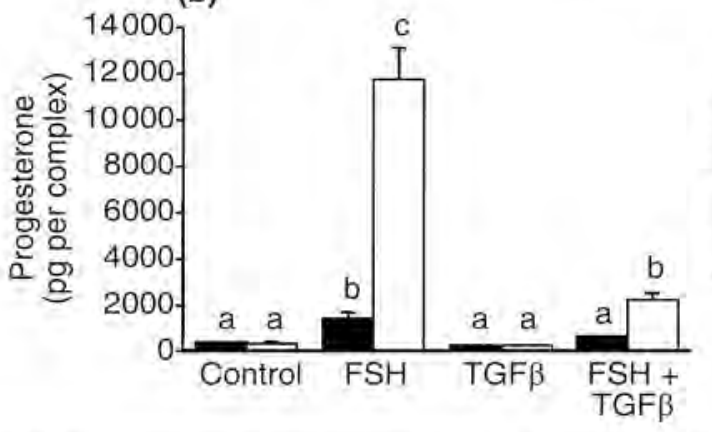

(c)

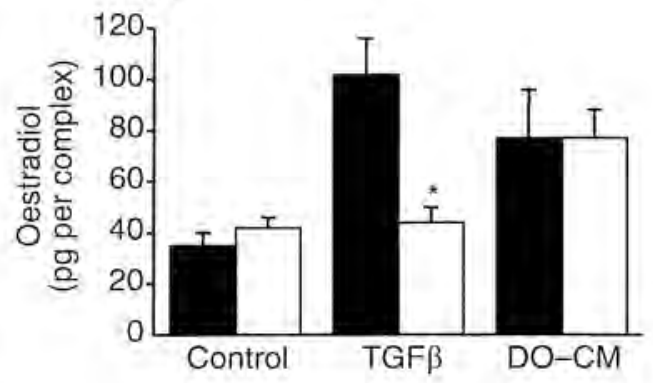

(d)

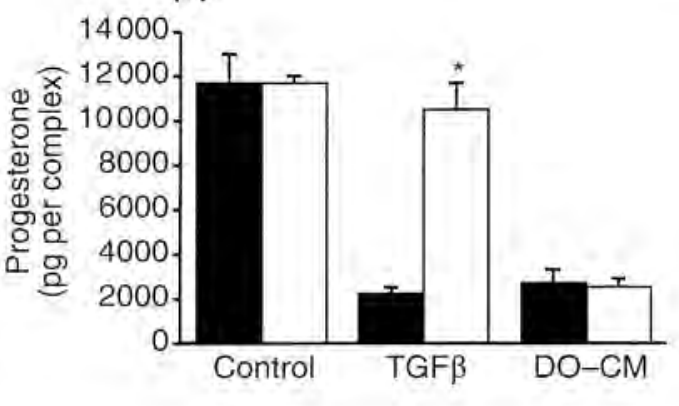

Fig. 2. Effect of transforming growth factor $\beta 1$ (TGF $\beta 1$ ) on oestradiol and progesterone production by intact cumulus-oocyte cell complexes (COCs) and oocytectomized (OOX) complexes of mice. $(\mathrm{a}, \mathrm{b}) \operatorname{COC}(\mathbf{)})$ and OOX $(\square)$ complexes were cultured in the presence of $100 \mathrm{ng}$ FSH $\mathrm{ml}^{-1}, 10 \mathrm{ng}$ TGF $\beta 1 \mathrm{ml}^{-1}$ or both, and (a) oestradiol and (b) progesterone production after $48 \mathrm{~h}$ was determined by radioimmunoassay. All treatments included testosterone as a substrate for oestradiol production. $(\mathrm{c}, \mathrm{d})$ OOX complexes were cultured for $48 \mathrm{~h}$ in the presence of TGF 31 or denuded oocyle-conditioned media (DO-CM) and in the presence ( $\square$ ) or absence ( of $5 \mu \mathrm{g}$ neutralizing antibodies $\mathrm{ml}^{-1}$ to TGF $\beta 1$. All treatments included FSH and testosterone to support steroid hormone production. Values are mean \pm SEM from three experiments and different letters above the bars indicale significant differences $(P<0.05)$. Asterisks indicate values significantly different from the same treatment without antibodies. $(P<0.05)$.

for COCs, or for OOX complexes cultured in oocyte-conditioned media. Neutralizing antibodies to TGF $\beta 1$ were effective at ablating the response of OOX complexes to TGF $\beta 1$, but had negligible effects on the expansion of OOX complexes cultured in oocyte-conditioned media, indicating that the TGF $\beta 1$ antibodies do not interfere with the actions of the oocyte-secreted CEEF.

\section{Effect of TGF $\beta 1$ on steroid hormone production by intact and OOX complexes}

Mouse oocytes secrete a factor that inhibits progesterone and enhances oestradiol production by FSH-stimulated cumulus granulosa cells (Vanderhyden et al,, 1993). As TGF 31 was able to mimic the effects of the oocyte-secreted CEEF, its actions on cumulus steroid hormone production were then compared with those of oocytes. As previously reported, $\mathrm{FSH}$ strongly stimulated oestradiol production (Fig. 2a) in COCs, an effect that was almost complefely eliminated by removal of the oocytes. Although TGFB1 alone had no effect on oestradiol production, it enhanced FSH-stimulated oestradiol production by OOX complexes to $62 \%$ of that of COCs. Although TGFB1 mimics the effect of the oocyte in promoting oestradiol 


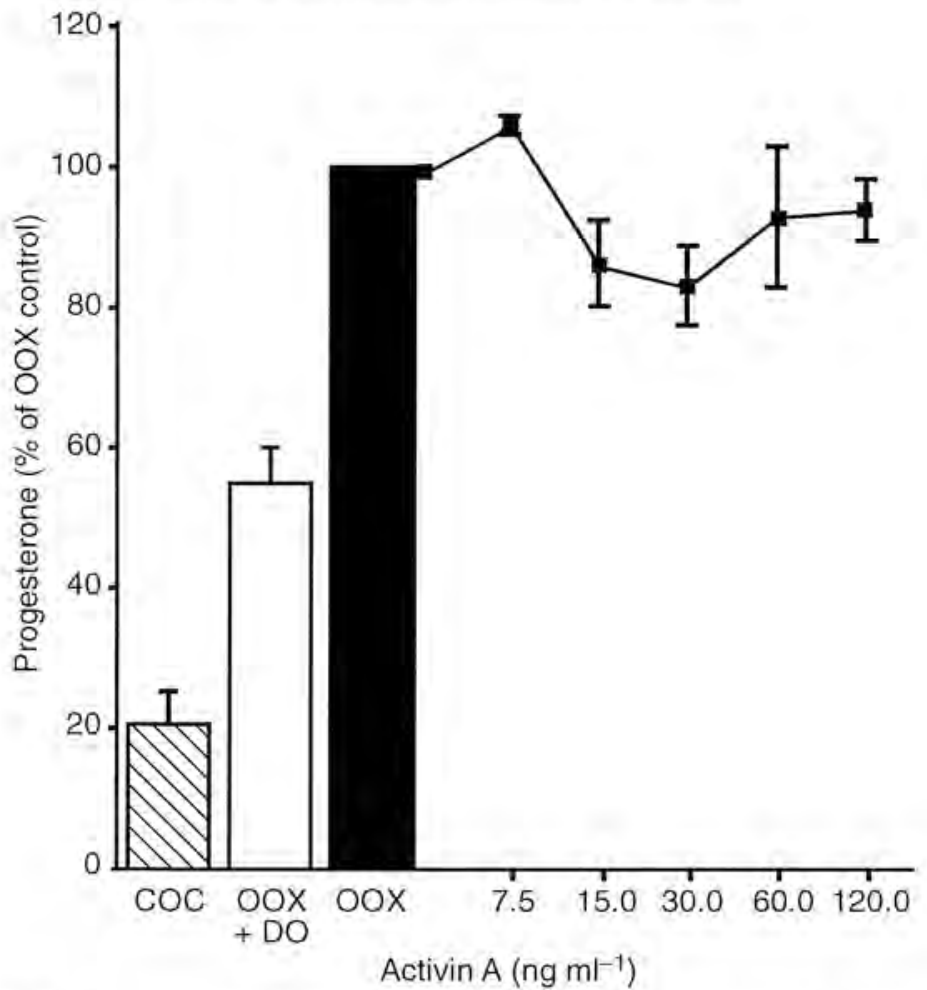

Fig. 3. Accumulation of progesterone in cultures of intact cumulus-oocyte complexes (COC) and oocytectomized (OOX) complexes and OOX complexes cultured in the presence of denuded oocytes $(\mathrm{OOX}+\mathrm{DO})$ or activin $\AA$. Complexes were isolated from mice treated with equine chorionic gonadotrophin and cultured for $30 \mathrm{~h}$ in the presence of FSH $\left(100 \mathrm{ng} \mathrm{ml}^{-1}\right)$, testosterone $\left(500 \mathrm{nmoll}^{-1}\right)$ and various concentrations of activin-A (7.5$120.0 \mathrm{ng} \mathrm{ml}^{-1}$ ). Values are mean \pm SEM from four experiments.

production, it does not appear to be the oocyte-secreted factor, as neutralizing antibodies to TGF $\beta 1$ could eliminate the effects of TGF $\beta 1$ on oestradiol production by OOX complexes (Fig. 2b), but failed to alter the amount of this hormone produced by OOX complexes in the presence of oocyte-conditioned media.

The effects of TGF $\beta 1$ on progesterone production were examined in a similar way. OOX complexes yielded significantly higher concentrations of progesterone in response to FSH stimulation compared with COCs, but this progesterone production was almost completely abolished in the presence of TGF $\beta 1$ (Fig. 2c). Neutralizing antibodies to TGF $\beta 1$ prevented the effects of TGF $\beta 1$ on progesterone production by OOX complexes, but had no effect when the OOX complexes were cultured in oocyte-conditioned media (Fig. 2d). Thus, although both oocytes and TGF $\beta 1$ promote oestradiol and inhibit progesterone production, the results indicate that TGF $\beta 1$ is not the oocyte-secreted steroid regulating factor.

\section{Effect of activin A on progesterone production by OOX complexes}

As activin has been reported to inhibit progesterone production by granulosa cells (Miró et $\mathrm{al}_{+}, 1991$ ), the hypothesis that activin might be the oocyte-secreted progesterone inhibitory 
Table 2. Effect of growth differentiation factor 9 (GDF-9) +1 - and -1 - denuded oocytes on cumulus expansion of mouse OOX complexes

\begin{tabular}{lccc}
\hline $\begin{array}{l}\text { Control/treatment } \\
\text { group }\end{array}$ & $\begin{array}{c}\text { Number of } \\
\text { ocytes used for } \\
\text { conditioning }\end{array}$ & $\begin{array}{c}\text { Number of } \\
\text { complexes } \\
\text { assessed }\end{array}$ & $\begin{array}{c}\text { Degree of } \\
\text { expansion } \\
(0 \text { to }+4)\end{array}$ \\
\hline COC & 0 & 15 & $3.3 \pm 0.3$ \\
OOX & 0 & 15 & 0 \\
OOX + GDF-9+/-MC & 25 & 20 & $3.3 \pm 0.2$ \\
OOX + GDF-9-/-MC & 25 & 20 & 0 \\
OOX + GDF-9-/-MI & 25 & 25 & 0 \\
\hline
\end{tabular}

Oocytectomized cumulus-oocyte cell complexes (OOX) were cultured in the presence of GDF-9 heterozygous ( $+/-)$ and homozygous $(-1-)$ oocytes. Control and treatment groups were cultured in $50 \mu \mathrm{I}$ Waymouth media with $5 \%$ fetal bovine serum under washed mineral oil for $16 \mathrm{~h}$ in the presence of FSH, The degree of expansion was determined on a scale from 0 (no expansion) to +4 (maximal response with all cumulus layers undergoing expansion). Values represent the mean \pm SEM of three experiments.

COC: cumulus-oocyte cell complexes; MC: meiotically competent oocytes; MI: meiotically incompelent oocytes.

factor was tested. FSH stimulated the accumulation of progesterone in cultures of OOX complexes to concentrations fivefold greater than in COCs (Fig. 3), and this accumulation was reduced when OOX complexes were cultured in the presence of denuded oocytes. Addition of activin A did not affect the progesterone production by OOX complexes at any concentration tested.

\section{Ability of GDF-9-deficient oocytes to enable cumulus expansion of OOX complexes}

GDF-9-deficient oocytes were co-cultured with OOX complexes, to provide additional evidence that GDF-9 may be the oocyte-secreted CEEF that enables expansion of cumulus cells. COCs, OOX and OOX complexes co-cultured with GDF-9 heterozygous oocytes were included as controls in the experiment (Table 2). As expected, COCs expanded (3.3 \pm 0.3 ), whereas no expansion was observed for OOX complexes cultured alone. GDF-9 heterozygous oocytes enabled the expansion of OOX complexes to near maximal levels $(3.3 \pm 0.2)$, whereas OOX complexes cultured with meiotically competent and incompetent GDF-9-deficient oocytes did not expand, indicating that the lack of GDF-9 production by these oocytes impairs their ability to enable cumulus expansion.

\section{Ability of GDF-9-deficient oocytes to regulate cumulus cell steroidogenesis}

Murine oocytes secrete a factor that stimulates cumulus cell oestradiol production, as evident from the significantly reduced production of oestradiol by OOX complexes ( $24 \pm$ $4.5 \%$ ) in comparison with the COCs (Fig. 4a). Co-culture of OOX complexes with GDF-9 heterozygous oocytes resulted in a marked increase in oestradiol production to $89 \%$ of that of COC. In contrast, GDF-9 homozygous, meiotically competent and incompetent oocytes failed to support oestradiol production by OOX complexes, indicating that, unlike normal oocytes, oocytes from GDF-9-deficient mice do not secrete the oestradiol-stimulatory factor.

COCs produced progesterone at concentrations of only $12 \%$ of that of OOX complexes, indicating the secretion of a progesterone-inhibitory factor by the oocyte (Fig. 4b). Similar amounts of progesterone production were observed for OOX complexes co-cultured with 
(a)

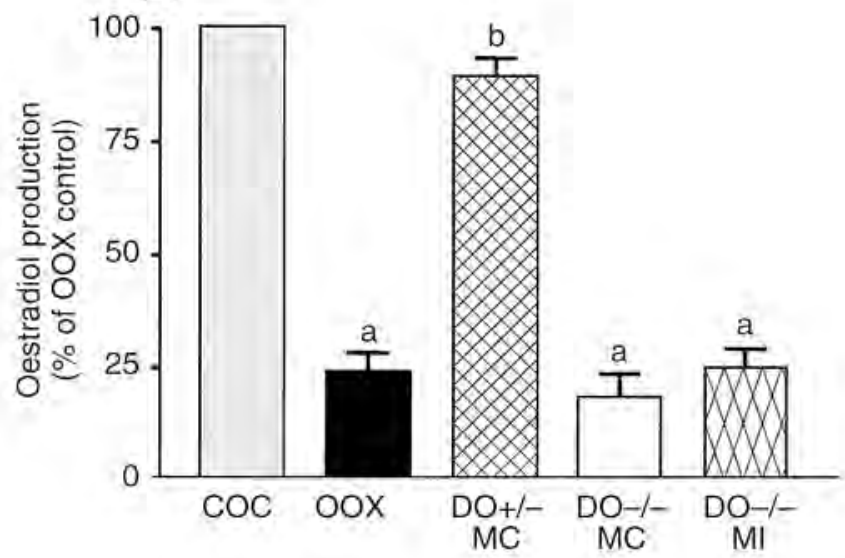

(b)

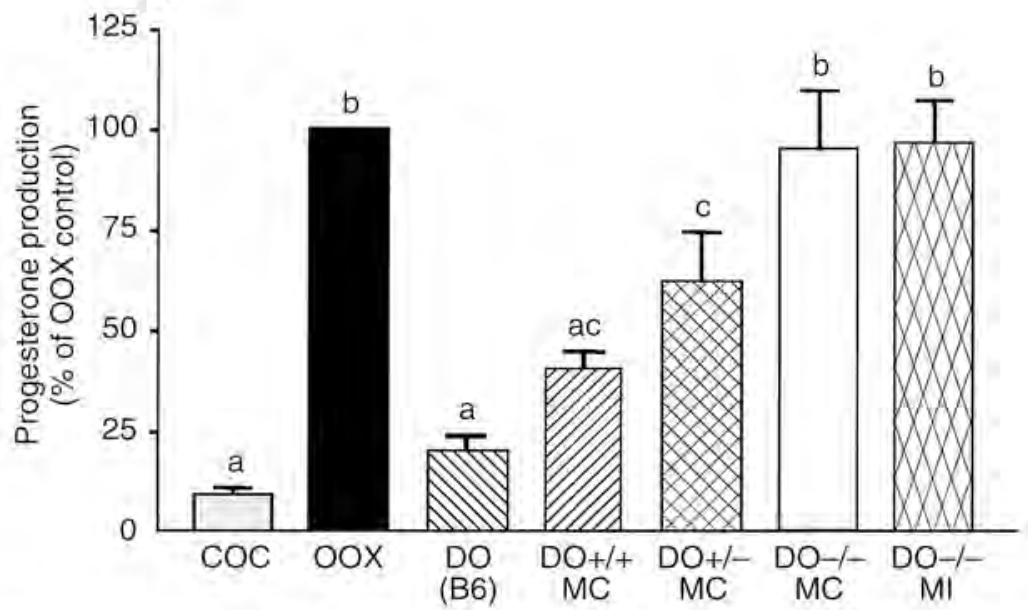

Fig. 4. (a) Oestradiol and (b) progesterone production by intact cumulusoocyte complexes (COCs) and oocytectomized complexes (OOX), and OOX complexes co-cultured with GDF-9 $(t /+,+1-,-1)$ denuded oocytes (DO) for $48 \mathrm{~h}$ in the presence of FSH and testosterone. Oocytes were separated as meiotically competent (MC) or incompetent (MI) based on their ability to undergo spontaneous meiotic resumption in culture. (b) The ability of GDF$9+1+$ DO and wild-type oocytes from $(\mathrm{C} 57 \mathrm{Bl} / 6 \times \mathrm{Balb} / \mathrm{c}) \mathrm{F}_{1}$, mice (denoted B6) were compared. Values are mean \pm SEM from three experiments and different letters above the bars indicate significant differences $(P<0.05)$.

$(\mathrm{C} 57 \mathrm{Bl} / 6 \times \mathrm{Balb} / \mathrm{C}) \mathrm{F}_{1}$ oocytes (27\% of that of OOX complexes alone) and GDF-9 wild type $(+/ 4)$ oocytes $(41 \%)$. However, the degree of suppression of progesterone production by OOX complexes was reduced in the presence of GDF-9 heterozygous oocytes $(70 \pm 15.5 \%)$. GDF-9-deficient $(-1-)$ meiotically competent $(94 \pm 16.4 \%$ ) and incompetent $(84 \pm 8 \%$ ) oocytes failed to inhibit progesterone production by OOX complexes. These results indicate a progesterone-inhibitory effect of GDF-9 on FSH-stimulated cumulus cells, and indicate that GDF-9 plays an integral role in the regulation of cumulus cell progesterone production. 


\section{Discussion}

Studies in the past decade have led to considerable advance in the study of folliculogenesis, most particularly because of the identification and early characterization of oocyte proteins involved in this process. Much of our understanding of the specific roles of the oocyte in follicle development is derived from studies that examined granulosa cell function after removal of the oocyte from preantral follicles or COCs. It has been demonstrated, using the procedure of oocytectomy, that oocytes are required for mouse cumulus expansion (Buccione et al., 1990; Vanderhyden et al., 1990), and that oocytes suppress luteinization (Vanderhyden et al., 1993; Vanderhyden and Tonary, 1995), inhibit expression of urokinase plasminogen activator and $\mathrm{LH}$ receptors in granulosa cells (Canipari et al., 1995; Eppig et al., 1997b) and regulate KL expression during follicle growth (Joyce et $a l_{+}, 1999$ ).

The various models of germ cell deficiency indicate that the presence of the oocyte is critical for preventing premature progesterone production by rodent follicles. Similar observations have been reported for pigs (Coskun et al, 1995), chickens (Tischkau and Bahr, 1996) and cows (Li et al., 2000) and have also been reported for Xenopus laevis oocytes, in which the presence of early-stage oocytes resulted in the follicle cells producing oestradiol rather than progesterone, an influence not dependent upon physical association with the oocyte (Sretarugsa and Wallace, 1997). Thus, it appears that the default steroidogenic pathway for granulosa cells in many species is the synthesis of progesterone, and the oocyte is key to the inhibition of this pathway.

To date, the molecules that mediate the influence of the oocyte on granulosa cell luteinization have not been identified, and the experiments reported here confirm that, despite the apparent similarities of the action of TGF $\beta 1$, activin and the oocyte on granulosa cell progesterone production, neither TGF 31 nor activin appears to be the oocyte-secreted luteinization inhibitory factor. GDF-9 remains a strong candidate, as GDF-9-deficient oocytes do not have the abilities of normal oocytes to promote oestradiol and suppress progesterone production. This latter observation is in agreement with the previous demonstration that recombinant GDF-9 suppresses FSH-induced progesterone production by rat granulosa cells (Vitt et al., 2000). In addition to its role in the inhibition of FSH-stimulated progesterone production, GDF-9 has been shown to have growth-promoting effects on granulosa cells, an action also shared with oocyte-conditioned media (Vanderhyden èt al., 1992). Thus, the diverse actions of GDF-9 could explain many of the regulatory effects of oocytes on granulosa cells. However, it should be noted that there are discrepancies in the action of GDF-9 that distinguish it from the apparent actions of oocytes. Although GDF-9 treatment alone enhances the expression of steroidogenic acute regulatory protein (Elvin et al., 1999a) and progesterone production in cultured granulosa cells, oocytes do not share this effect. In addition, the possibility remains that GDF-9 is not the only factor missing from the oocytes obtained from the GDF-9-deficient mice, and that these oocytes are otherwise deficient as a consequence of their aberrant follicle development. Thus, it cannot yet be concluded that GDF-9 is the oocyte-secreted luteinization inhibitory factor; the development of a neutralizing antibody would greatly facilitate further studies in this area.

Activin, although initially characterized as a gonadal hormone that regulates the pituitary release of FSH (Ling et al., 1986; Vale et al., 1986), may have a role in the regulation of oocyte activity. Activin is produced by granulosa cells (Findlay, 1993) and oocytes (Albano et al., 1993), and both oocytes and granulosa cells have activin receptors (Wu et al, 1994; Drummond et al., 2002). Previous studies have demonstrated the development-dependent effects of activin on granulosa cell steroidogenesis, such that aromatase activity is enhanced 
and progesterone production is suppressed as follicular maturation progresses (Miró et al., 1991). These steroidogenic responses to activin treatment are similar to that of the oocytesecreted steroid-regulating factor, raising the possibility that activin is the oocyte-secreted factor. However, in contrast to the inhibitory effects of oocytes on cumulus cell progesterone production, this study revealed no effect of activin on either intact or OOX complexes, indicating that activin is less effective on cumulus cells than on granulosa cells. In addition, it appears that the timing of granulosa cell sensitivity to activin is opposite to their sensitivity to the oocyte-secreted factor. Immature granulosa cells were insensitive to activin but gained sensitivity in luteinized granulosa cells (Miró et al., 1991), whereas the process of luteinization reduces the responsiveness to oocytes (Vanderhyden, 1996). This temporal discordance between granulosa cell responsiveness to activin versus oocytes indicates that it is unlikely that activin is the oocyte-secreted factor that inhibits progesterone production.

At least two other members of the TGF $\beta$ superfamily have actions that inhibit luteinization: BMP-6 and BMP-15. BMP-6 has no effect on granulosa cell proliferation, but has been shown to produce a marked decrease in FSH-induced progesterone production and, thus, shares a specific activity with oocytes (Otsuka etal,, 2001a). Similarly, the ability of BMP-15 to suppress FSH-stimulated progesterone production (Otsuka et al., 2000) warrants further investigation of both of these growth factors as the oocyte-secreted luteinization inhibitor. However promising because of their shared effects with the oocyte in the inhibition of progesterone production, it should be noted that the mechanism of action of the oocyte activity and the BMPs are markedly different. Unlike the oocyte-secreted factors the site of action of which appears to be downstream of the generation of CAMP (Buccione et al., 1990), BMP-6 appears to downregulate FSH-stimulated adenylate cyclase activity (Otsuka et al., 2001a). Likewise, BMP-15 seems to act by reducing the expression of FSH receptors (Otsuka et al., 2001b) and, therefore, neither of these factors are likely to be the oocyte-secreted factor that regulates cumulus expansion or steroid hormone production.

In addition to its ability to regulate progesterone production, TGF $\beta 1$ mimics the actions of oocytes in enabling the expansion of OOX complexes. However, as neutralizing antibodies to TGF $\beta 1$ fail to prevent the expansion promoting action of oocytes, it is unlikely that TGF $\beta 1$ is the oocyte-secreted CEEF. Although the results reported here were confined to mouse oocytes, it should be noted that in preliminary experiments, there was no effect of neutralizing antibodies to TGF 31 on FSH-induced expansion of pig COCs $(n=30)$ or OOX complexes $(n=30)$. In experiments using conditioned media from germinal vesicle-stage pig oocytes and mouse OOX complexes, TGFß1 neutralizing antibodies did not inhibit FSH-induced expansion of mouse OOX complexes cultured in oocyte-conditioned media. These results are in agreement with previous work on isolated cumulus cells indicating that the oocytesecreted factor that enables cumulus expansion is not TGFB1 (Salustri et al., 1990; Tirone et al., 1997).

GDF-9 upregulates expression of HAS-2, the major hyaluronic acid synthase involved in cumulus expansion, and inhibits the protease UPA, an enzyme suppressed during production of the hyaluronic acid extracellular matrix (Elvin et al., 1999a). GDF-9 can also stimulate the expansion of OOX complexes, rendering this growth factor a prime candidate for the oocyte-secreted cumulus expansion enabling factor. The present study adds evidence to support this hypothesis by showing that oocytes from GDF-9-deficient mice are not able to support expansion of OOX complexes. Although most of the current evidence indicates that GDF-9 is the CEEF, the possibility remains, as noted above, that the oocytes obtained from the GDF-9-deficient mice may be otherwise deficient as a consequence of their aberrant follicle development. In addition, there is a discrepancy in the 
timing of expression of GDF-9 versus CEEF in oocytes that needs to be explained. GDF-9 is expressed in oocytes very early in follicle development (McGrath et al., 1995), whereas CEEF is not secreted by oocytes until about the time of acquisition of meiotic competence. This study took advantage of the fact that many of the oocytes from GDF-9 deficient mice failed to undergo spontaneous meiotic resumption to compare the ability of meiotically competent versus incompetent oocytes to support cumulus expansion. However, the actions of the two subpopulations of oocytes did not differ. Thus, although GDF-9 remains the primary candidate for CEEF, there are some discrepancies that still need to be resolved.

The present study and other studies have shown that it is not uncommon for several members of the TGF $\beta$ superfamily to mimic the actions of the oocytes on granulosa or cumulus cell function in vitro, and it appears that TGF $\beta 1$ can mimic several of these actions. However, the fact that the growth factor has the appropriate action is clearly not sufficient to conclude that it plays this role in the physiological context, and more work still needs to be done to determine the specificity of action of the various members of the TGF $\beta$ superfamily during follicle development. Another example of this is the regulation of KL expression. Fully grown oocytes suppress KL expression (Joyce et al., 2000), and this action may be mediated by GDF-9, as recombinant GDF-9 can also inhibit KL expression (Joyce et al., 2000) and the ovaries of GDF-9-deficient mice show an increase in the number of KL transcripts (Elvin et al., 1999b). However, TGFB1 has inhibitory effects on the expression of KL mRNA in ovarian surface epithelial cells (Ismail et al., 1999) and, although its effects on granulosa cells are not yet determined, the possibility remains that both GDF-9 and TGF 1 elicit the same response in granulosa cells, and the potential interactions between these two growth factors require elucidation. In addition, it is clear that the interactions that need to be studied are not confined to these two growth factors, as there is now evidence that another oocyle-secreted factor, BMP-15, can stimulate KL expression in rat granulosa cells (Otsuka and Shimasaki, 2002). Although these interactions are likely to be quite complex, the consequence of this plethora of newly identified oocyte-secreted factors has been to give potential identity to oocyte factors previously described only by their actions and to turn the investigation of follicle development into a dynamic area of study. The molecular definition of the oocyte-granulosa cell interactions has generated a complex model of the regulatory mechanisms controlling follicle growth that promises to become even more complex (Fig. 5).

The aberrant folliculogenesis found in GDF-9 and BMP-15 deficient mice (Dong et al., 1996; Yan et al., 2001) has led to the investigation of these factors in domestic ruminant and human ovarian function. Both factors are expressed in human oocytes (Teixeira et al., 2002), and there are no mutations associated with these genes in women with premature ovarian failure or polycystic ovary syndrome (Takebayahsi et al., 2000); however, the expression of GDF-9 has been reported to be reduced in polycystic ovaries (Teixeira et al., 2002). Treatment of human cortical tissue slices with GDF-9 in vitro enhanced both follicle survival and progression of follicular development to the secondary stage, indicating that this growth factor may have clinical utility in designing culture conditions for human follicles (Hreinsson et al., 2002). Mutations in BMP-15 or BMP receptor type $1 \mathrm{~B}$ revealed the importance of this pathway in the regulation of follicular development and ovulation in sheep (Galloway et al., 2000; Mulsant et al., 2001; Souza et al., 2001; Wilson et al., 2001), with the interesting observation that BMP-15 mutations caused increased ovulation rate and infertility in a dosedependent manner (Galloway et al., 2000). The role of oocyte-derived TGF $\beta$ superfamily members in sheep folliculogenesis and ovulation are described in detail by K. McNatty et al. (this supplement). 
Pituitary gland

$\mathrm{FSH}$

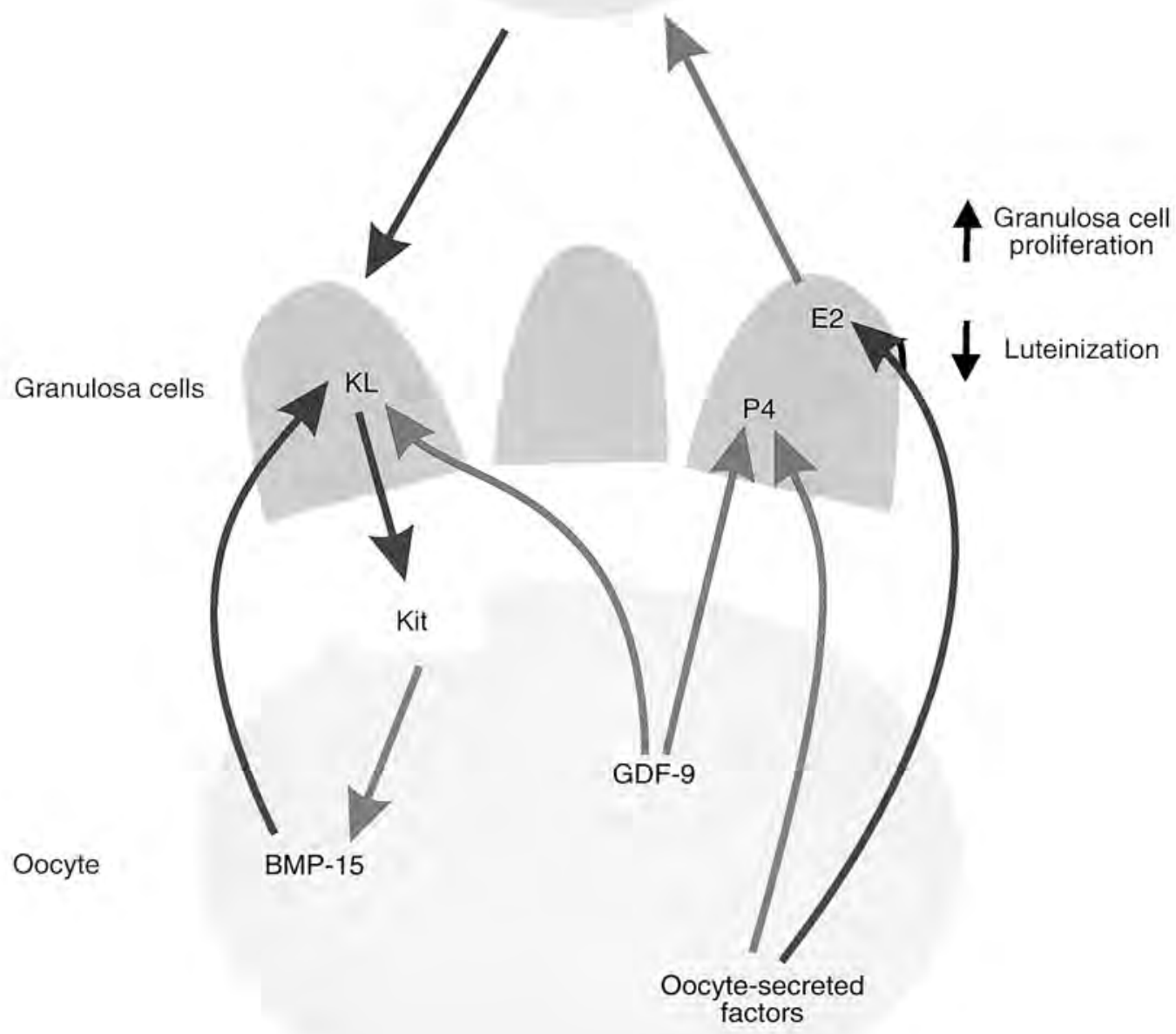

Fig. 5. Model showing paracrine and hormonal factors controlling oocyte growth and follicle development. Oocyte-secreted factors, including bone morphogenetic factor 15 (BMP-15), growth differentiation factor 9 (GDF-9) and other factors yet to be identified, act on the granulosa cells to regulate Kit ligand expression and steroid hormone production to enhance follicle development and the inhibition of luteinization. GDF-9 may be the oocyte-secreted factor that inhibits cumulus cell progesterone (P4) production; however, the factor that promotes oestradiol (E2) production is still unknown. The expression of kit ligand $(\mathrm{KL})$ is regulated by several factors, including $\mathrm{FSH}$ and at least two factors produced by the oocyte that have opposing actions, one of which is stimulatory (BMP-15) and the other inhibitory (GDF-9). Kit ligand acts through Kit receptors to promote oocyte growth. Green arrows indicate stimulatory actions; red arrows indicate actions that are inhibitory. 


\section{Conclusion}

The increasing number of growth factors belonging to the TGF $\beta$ superfamily and often showing unique expression in the ovary has provided extensive opportunities to explore their expression and function during follicle development, and will ideally reveal the biochemical identities for the oocyte factors that until now have been detectable only by their biological activities. GDF-9 remains the most likely candidate for the oocyte-secreted cumulus expansion enabling factor, and the oocyte-secreted steroid-regulatory factor that inhibits luteinization; however, there are discrepancies that need to be resolved. Future studies will also need to elucidate the cross-modulation between the TGF $\beta$ family members and the gonadotrophins, the interplay between the various TGF $\beta$ family members, and the modulation of their activity by regulatory proteins, such as follistatin. The investigation of the biochemical interactions and physiological consequences of these molecules in the complex, finely controlled mechanisms regulating follicle growth promises to be a dynamic area of study for some time.

The authors are grateful to M. Matzuk for generously providing the GDF-9 knockout mice, to A. Schneyer for providing the activin, and to the NIDDK through the National Hormone and Pituitary Program (University of Maryland School of Medicine) for donating the FSH used in these experiments. The authors extend their thanks to D. T. Armstrong for supplying the progesterone and oestradiol antibodies for the radioimmunoassays, and J-F. Ethier for his critical review of this manuscript. This work was funded by a grant from the Canadian Institutes of Health Research (B. C. Vanderhyden) and in part by a fellowship from the OECD Co-operative Research Program and Grant A $5045102 / 01$ from the Grant Agency of Academy of Sciences of the Czech Republic (E. Nagyova).

\section{References}

Albano RM, Groome N and Smith JC (1993) Activins are expressed in preimplantation mouse embryos and in ES and EC cells and are regulated on their differentiation Development 117 711-723

Bodensteiner KJ, Clay CM, Moeller CL and Sawyer HR (1999) Molecular cloning of the ovine growth/ differentiation factor 9 gene and expression of growth/differentiation factor-9 in ovine and bovine ovaries Biology of Reproduction $60381-386$

Buccione R, Vanderhyden BC, Caron PJ and Eppig JJ (1990) FSH-induced expansion of the mouse cumulus oophorus in vitro is dependent upon a specific factor(s) secreted by the oocyte Developmental Biology $13816-25$

Canipari R, Epifano O, Siracusa G and Salustri A (1995) Mouse oocytes inhibit plasminogen activator production by ovarian cumulus and granulosa cells Developmental Biology $167371-378$

Coskun S, Uzumcu M, Lin YC, Friedman CI and Alak BM (1995) Regulation of cumulus cell steroidogenesis by the porcine oocyte and preliminary characterization of oocyte-produced factor(s) Biology of Reproduction 53 670-675

Dong J, Albertini DF, Nishimori K, Kumar TR, Lu N and Matzuk MM (1996) Growth differentiation factor-9 is required during early ovarian folliculogenesis Nature $383531-535$

Drummond $A E$, Le MT, Ethier IF, Dyson $M$ and Findlay JK (2002) Expression and localization of activin receptors, Smads and beta glycan to the postnatal rat ovary Endocrinology 143 1423-1433

Dube JL, Wang P, Elvin J, Lyons KM, Celeste AJ and Matzuk MM (1998) The bone morphogenetic protein 15 gene is $X$-linked and expressed in oocytes Molecular Endocrinology 12 1809-1817

El-Fouly MA, Cook B, Nekola $M$ and Nalbandov AV (1970) Role of the ovum in follicular luteinization Endocrinology 87 288-293

Elvin JA, Clark AT, Wang P, Wolfman NM and Matzuk MM (1999a) Paracrine actions of growth differentiation factor 9 in the mammalian ovary Molecular Endocrinology 13 1035-1048

Elvin JA, Yan C, Wang P, Nishimori $K$ and Matzuk MM (1999b) Molecular characterization of the follicle defects in the growth differentiation factor 9-deficient ovary Molecular Endocrinology 13 1018-1034

Eppig IJ, Chesnel F, Hirao $\mathrm{Y}, \mathrm{O}^{\prime}$ Brien MJ, Pendola FL, Watanabe S and Wigglesworth K (1997a) Oocyle control of granulosa cell development: how and why? Human Reproduction 12 127-132

Eppig JJ, Wigglesworth $K$, Pendola $F$ and Hirao $Y$ (1997b) Murine oocytes suppress expression of luteinizing hormone receptor messenger ribonucleic acid by granulosa cells Biology of Reproduction $\mathbf{5 6}$ 976-984

Findlay J (1993) An update on the roles of inhibin, activin and follistatin as local regulators of folliculogenesis Biology of Reproduction 48 15-23 
Galloway SM, McNatty KP, Cambridge LM et al. (2000) Mutations in an oocyte-derived growth factor gene (BMP15) cause increased ovulation rate and infertility in a dosage-sensitive manner Nature Genetics 25 279-283

Gilchrist RB, Ritter LJ and Armstrong DT (2001) Mouse oocyte mitögenic activity is developmentally coordinated throughout folliculogenesis and meiotic maturation Developmental Biology 240289 298

Heller DT and Schultz RM (1980) Ribonucleoside metabolism by mouse oocytes: metabolic cooperativity between the fully grown oocyte and cumulus cells Journal of Experimental Zoology 214 355-364

Hreinsson JG, Scott JE, Rasmussen C, Swahn ML, Hsueh A) and Hovatta O (2002) Growth differentiation factor-9 promotes the growth, development and survival of human ovarian follicles in organ culture Journal of Clinical Endocrinology and Metabolism $87316-321$

Hubbard GM and Erickson GF (1988) Luteinizing hormone-independent luteinization and ovulation in the hypophysectomized rat: a possible role for the oocyte? Biology of Reproduction 39 183-194

Ismail R, Okawara Y, Fryer JN and Vanderhyden BC (1996) Hormonal regulation of the ligand for the $c$ kit proto-oncogene in the ovary and its effects on spontaneous oocyte meiotic maturation Molecular Reproduction and Development 43 458-469

Ismail RS, Cada M and Vanderhyden BC (1999) Transforming growth factor $-\beta$ regulates Kit ligand expression in rat ovarian surface epithelial cells Oncogene 18 4734-4741

Joyce IM, Pendola FL, Wigglesworth $\mathrm{K}$ and Eppig JJ (1999) Oocyte regulation of kit ligand expression in mouse ovarian follicles Developmental Biology 214 342-353

Joyce IM, Clark AT, Pendola FL and Eppig II (2000) Comparison of recombinant growth differentiation factor-9 and oocyle regulation of KIT ligand messenger ribonucleic acid expression in mouse ovarian follicles Biology of Reproduction 63 1669-1675

Lanuza GM, Fischman ML and Baranao JL (1998) Growth promoting activity of oocytes on granulosa cells is decreased upon meiotic maturation Developmental Biology 197 129-139

Li R, Norman RJ, Armstrong DT and Gilchrist RB (2000) Oocyte-secreted factor(s) determine functional differences between bovine mural granulosa cells and cumulus cells Biology of Reproduction 63 839845

Ling N, Ying SY, Ueno N, Shimasaki S, Esch F, Hotta M and Guillemin R (1986) Pituitary FSH is released by a heterodimer of the $\beta$ subunits from the two forms of inhibin Nature 321 779-782

McGrath SA, Esquela AF and Lee SJ (1995) Oocytespecific expression of growth/differentiation factor-9 Molecular Endocrinology 9 131-136
Manova K, Huang EJ, Angeles M, De Leon V, Sanchez S, Pronovost SM, Besmer P and Bachvarova RF (1993) The expression pattern of the $c$-kit ligand in gonads of mice supports a role for the c-kit receptor in oocyte growth and in proliferation of spermatogonia Developmental Biology $15785-99$

Miró F, Smyth CD and Hillier SG (1991) Developmentrelated effects of recombinant activin on steroid synthesis in rat granulosa cells Endocrinology 1293388 3394

Mulsant P, Lecerf F, Fabre $S$ et al, (2001) Mutation in bone morphogenetic protein receptor-1B is associated with increased ovulation rate in Booroola Merino ewes Proceedings National Academy of Sciences USA 98 5104-5109

Nekola MV and Nalbandov AV (1971) Morphological changes of rat follicular cells as iniluenced by oocytes Biology of Reproduction 4 154-160

Otsuka F and Shimasaki S (2002) A negative feedback system between oocyte bone morphogenetic protein 15 and granulosa cell kit ligand: its role in regulating granulosa cell mitosis Proceedings National Academy of Sciences USA 99 8060-8065

Otsuka F, Yao Z, Lee T, Yamamoto S, Erickson GF and Shimasaki S (2000) Bone morphogenetic protein-15. Identification of target cells and biological functions Journal of Biological Chemistry $27539523-39528$

Otsuka F, Moore RK and Shimasaki S (2001 a) Biological function and cellular mechanism of bone morphogenetic protein- 6 in the ovary Journal of Biological Chemistry 276 32 889-32 895

Otsuka F, Yamamoto S, Erickson GF and Shimasaki S (2001b) Bone morphogenetic protêin-15 inhibits follicle-stimulating hormone ( $\mathrm{FSH}$ ) action by suppressing FSH receptor expression Journal of Biological Chemistry $27611387-11392$

Packer Al, Hsu YC, Besmer P and Bachvarova RF (1994) The ligand of the c-kit receptor promotes oocyte growth Developmental Biology 161 194-205

Ralph JH, Telfer EE and Wilmut I (1995) Bovine cumulus cell expansion does not depend on the presence of an oocyte secreted factor Molecular Reproduction and Development 42 248-253

Rebagliati MR and Dawid IB (1993) Expression of activin transcripts in follicle cells and oocytes of Xenopus laevis. Developmental Biology 159 574580

Salustri A, Ulisse S, Yanagishita $M$ and Hascall VC (1990) Hyaluronic acid synthesis by mural granulosa cells and cumulus cells in vitro is selectively stimulated by a factor produced by oocytes and by transforming growth factor-beta Journal of Biological Chemistry 265 19517-19523

Souza CJH, MacDougall C, Campbell BK, McNeilly AS and Baird DT (2001) The Booroola (FecB) phenotype is associated with a mutation in the bone morphogenetic receptor type $1 \mathrm{~B}$ (BMPRTB) gene Journal of Endocrinology 169 R1-R6 
Sretarugsa P and Wallace RA (1997) The developing Xenopus oocyte specifies the type of gonadotropinstimulated steroidogenesis performed by its associated follicle cells Development, Growth and Differentiation 39 87-97

Takebayashi K, Takakura K, Wang H, Kimura F, Kasahara K and Noda Y (2000) Mutation analysis of the growth differentiation factor-9 and $-9 B$ genes in patients with premature ovarian failure and polycystic ovary syndrome Fertility and Sterility $\mathbf{7 4} 976$ 979

Teixeira Filho FL, Baracat EC, Lee TH, Suh CS, Matsui M, Chang RJ, Shimasaki S and Erickson GF (2002) Aberrant expression of growth differentiation factor-9 in oocytes of women with polycystic ovary syndrome Journal of Clinical Endocrinology and Metabolism 87 1337-1344

Tirone $E$, D'Alessandris C, Hascall VC, Siracusa G and Salustri A (1997) Hyaluronan synthesis by mouse cumulus cells is regulated by interactions between follicle-stimulating hormone (or epidermal growth factor) and a soluble oocyte factor (or transforming growth factor beta 1) Journal of Biological Chemistry $2724787-4794$

Tischkau SA and Bahr JM (1996) Avian germinal disc region secretes factors that stimulate proliferation and inhibit progesterone production by granulosa cells Biology of Reproduction 53 670-675

Vale W, Rivier J, Vaughan J, McClintock R, Cornigan A, Woo W, Karr D and Spiess J (1986) Purification and characterization of an FSH releasing protein from porcine ovarian follicular fluid Nature $321776-779$

Vanderhyden BC (1993) Species differences in the regulation of cumulus expansion by an oocyte-secreted factor(s) Journal of Reproduction and Fertility 98 219-227

Vanderhyden BC (1996) Oocyte-secreted factors regulate granulosa cell steroidogenesis Zygote 4 317-321

Vanderhyden BC and Tonary AM (1995) Differential regulation of progesterone and estradiol production by mouse cumulus and mural granulosa cells by a factor(s) secreted by the oocyte Biology of Reproduction 53 1243-1250

Vanderhyden BC, Caron PJ, Buccione R and Eppig JJ (1990) Developmental pattern of the secretion of $\mathrm{cu}$ mulus expansion-enabling factor by mouse oocytes and the role of oocytes in promoting granulosa cell differentiation Developmental Biology 140 307-317

Vanderhyden BC, Telfer EE and Eppig JJ (1992) Mouse oocytes promote proliferation of granulosa cells from preantral and antral follicles in vitro. Biology of Reproduction 46 1196-1204

Vanderhyden BC, Cohen JN and Morley P (1993) Mouse oocytes regulate granulosa cell steroidogenesis Endocrinology 133 423-426

Vitt UA, Hayashi M, Klein C and Hsueh AJ (2000) Growth differentiation factor-9 stimulates proliferation but suppresses the follicle-stimulating hormoneinduced differentiation of cultured granulosa cells from small antral and preovulatory rat follicles Biology of Reproduction 262 370-377

Wilson T, Wu XY, Juengel JL et al. (2001) Highly prolific Booroola sheep have a mutation in the intracellular kinase domain of bone morphogenetic protein IB receptor (ALK-6) that is expressed in both oocytes and granulosa cells Biology of Reproduction 641225 1235

Wu T-CJ, Jih MH, Wang L and Wan Y-JY (1994) Expression of activin receptor II and IIB MRNA isoforms in mouse reproductive organs and oocytes. Molecular Reproduction and Development 38 9-15

Yan C, Wang P, DeMayo J et al. (2001) Synergistic roles of bone morphogenetic protein 15 and growth differentiation factor 9 in ovarian function Molecular Endocrinology $15854-866$

Yoshida H, Takakura N, Kataoka H, Kunisada T, Okamura H and Nishikawa SI (1997) Stepwise requirement of $\mathrm{c}$-kit tyrosine kinase in mouse ovarian follicle development Developmental Biology $\mathbf{1 8 4}$ 122-137 